Article

\title{
Mechanism Research and Countermeasure Analysis of Yellow Plume during the Gas Turbine Start-Up Period
}

\author{
Zhitan Liu ${ }^{1}$, Yugang $\mathrm{Li}^{1, *}$, Kai Wang ${ }^{1}$, Weiwei Shao ${ }^{2}$, Bo Wang ${ }^{2}$ and Chen Sun ${ }^{2}$ \\ 1 GUODIAN Environmental Protection Research Institute Co. Ltd., No. 10 Pu dong Road, \\ Nanjing 210000, China; zhitanliu@163.com (Z.L.); ernest_1999@163.com (K.W.) \\ 2 Insititute of Engineering Thermophysics, Chinese Academy of Sciences, No. 11 North Fourth Ring West \\ Road, Beijing 100190, China; shaoww@iet.cn (W.S.); wangbo@iet.cn (B.W.); sunchen@iet.cn (C.S.) \\ * Correspondence: liyugangxin@163.com
}

Received: 25 October 2018; Accepted: 7 January 2019; Published: 11 January 2019

\begin{abstract}
The problem of yellow plume exists in most heavy-duty gas turbine units under start-up and low load conditions. How to suppress the yellow plume is a difficult problem in gas turbine power plants. It is judged that yellow plume is caused by the high $\mathrm{NO}_{2}$ concentration in flue gas. From the point of view of mechanism research, this study analyzed the causes of yellow plume by numerical simulation combined with experimental research; obtained influence factors of the conversion of $\mathrm{NO}$ into $\mathrm{NO}_{2}$; analyzed the degree of influence of these factors on the formation of yellow plume; verified the results through on-site measurement of a 6FA gas turbine unit; and finally proposed the countermeasures to suppress yellow plume from the gas turbine side and the heat recovery steam generator (HRSG) side.
\end{abstract}

Keywords: gas turbine; start-up; yellow plume; $\mathrm{NO}-\mathrm{NO}_{2}$ conversion; control strategy

\section{Introduction}

Gas-fired power generation is cleaner and more efficient than coal-fired power generation, thus, in recent years, China's installed capacity of natural gas power generation has expanded rapidly under the background of increasing economic affordability. By the end of 2017, the installed capacity of China's natural gas power generation projects was 75.7 gigawatts, accounting for $4.3 \%$ of the total installed capacity of the country. According to the "13th Five-Year China electricity plan", China's installed capacity of gas power generation projects will reach 110 million kilowatts in 2020. As China's gas-fired power plants are mainly located in economically developed and environmentally sensitive areas, the pollutant emission standards of gas power plants are getting higher and higher [1,2]. At present, the emission problem of yellow plume of the gas turbine still exists in most domestic heavy-duty gas turbine units under start-up and low load conditions, as shown in Figure 1. How to suppress yellow plume is a difficult problem to be solved urgently in gas power plants. It is judged that yellow plume is caused by the increase of $\mathrm{NO}_{2}$ content in flue gas. From the point of view of mechanism research, this study used numerical simulation combined with experimental research to analyze the causes of yellow plume and obtain the influence factors of yellow plume. Combined with the on-site measurement results of one 6FA gas turbine unit, the study analyzed and verified the preceding results, and gave the countermeasures to suppress yellow plume. 


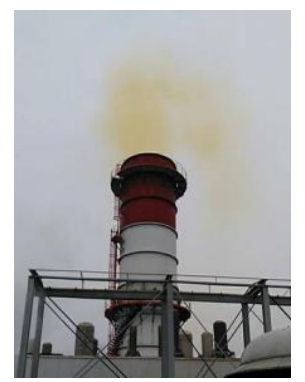

Figure 1. The yellow plume during the start-up period.

\section{Research Progress}

\subsection{International Research Progress}

Tuttle, Shisler and Mellor [3] studied the yellow plume phenomenon of gas turbine exhaust, showing that the emitted nitrogen oxides contained more $\mathrm{NO}_{2}$. Laurendeay [4] proposed simple mechanism conditions for $\mathrm{NO}$ decomposition and $\mathrm{NO}_{2}$ formation in typical combustion. Chen [5] found that the higher is the $\mathrm{CH}_{4}$ ratio, the higher is the proportion of $\mathrm{NO}_{2}$ in the product $\mathrm{NOx}$ by changing the ratio of $\mathrm{H}_{2}-\mathrm{CH}_{4}$ in the fuel.Klaus [6] and others conducted studies on the spectral measurement of NOx and successfully developed a system that can measure gas turbine exhaust. Feitelberg and Correa [7] simulated the chemical reaction of the turbine exhaust in the heat recovery steam generator (HRSG). The calculations show that $\mathrm{CO}$ and $\mathrm{NO}$ in flue gas can promote oxidation to generate $\mathrm{NO}_{2}$ at less than $800^{\circ} \mathrm{C}$. However, this study lacks in-depth analysis and experimental study of the effects of $\mathrm{CO}$ volume fraction, $\mathrm{NO}$ volume fraction, temperature, steam volume fraction and other components. Sorrentino, Sabia, Bozza, Ragucci and Joannon [8] found that internal exhaust gas recirculation represents a promising strategy to stabilize the oxidation process for new technologies that limit system temperatures to reduce pollutants (NOx and CO) emissions. Galbiati, Cavigiolo, Effuggi, Gelosa and Renato [9] studied the possibility of reducing fuel-NOx emissions using a laboratory-scale burner for mild combustion. However, neither Sorrentino nor Galbiatit analyzed the influencing factors of $\mathrm{NO}_{2}$ formation, mainly discussing the influencing factors of $\mathrm{NOx}$ formation instead.

\subsection{Research Progress in China}

Xu Wei [10] measured the smoke composition of GE's STAG 109FA SS gas turbine and its matched three-pressure reheat HRSG. The unit has a $\mathrm{NO}_{2}$ volume fraction of $67 \times 10^{-6}$ between $25 \mathrm{MW}$ and $80 \mathrm{MW}$ load, and the smoke is reddish brown. When the load is between $80 \mathrm{MW}$ and $125 \mathrm{MW}$, $\mathrm{NO}_{2}$ volume fraction can reach $23 \times 10^{-6}$, and the smoke is yellow.

Through the measurement of the flue gas composition during the start-up period of the gas turbine, Wang Weiqun [11] and others analyzed that the smoke from the chimney is mainly caused by $\mathrm{NO}_{2}$ in the flue gas and presented a proposal to reduce NOx emissions, but did not thoroughly analyze the influencing factors of yellow smoke or study the influence of flue gas parameters in the HRSG on the formation of yellow plume.

\section{Study on the Mechanism of Yellow Plume}

Two methods were used to study the mechanism of yellow plume of gas turbines: numerical simulation and experimental research.

\subsection{Numerical Simulation}

This project was aimed at studying the turbine exhaust conditions during the start-up period of the gas and steam combined cycle [12,13], using CHEMKIN simulation method which is a subroutine that can be used to solve chemical problems with flowing combustion processes. [14]. By changing the temperature of the flue gas and the volume fraction of $\mathrm{O}_{2} / \mathrm{CO} / \mathrm{H}_{2} \mathrm{O}$ in the flue gas, this study 
investigated the influence of various factors on the conversion of $\mathrm{NO}$ to $\mathrm{NO}_{2}$, which would provide a theoretical basis for finding a feasible and effective method to suppress yellow plume.

As shown in Figure 2, the plug-flow model was used to calculate the reaction law of NO conversion to $\mathrm{NO}_{2}$ under a certain flue gas condition and residence time, and the model put forward the following five hypotheses: (1) the flow of reactants is in steady state; (2) the reactants do not mix in the flow direction; (3) the reactants is in a one-dimensional flow state on the radial direction; (4) the model ignores the role of viscous force; and (5) the reactants meet ideal gas properties.

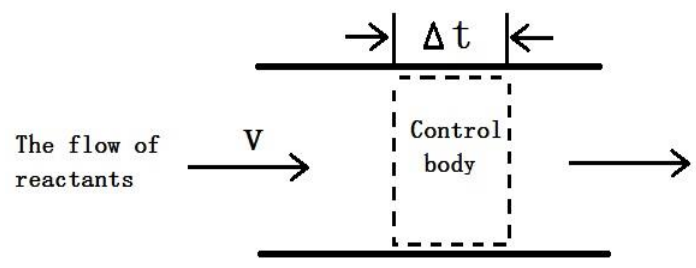

Figure 2. The plug-flow model.

The volume percentages of reactants components of the gas turbine under the basic operating conditions are: $\mathrm{CO}, 50 \times 10^{-6} ; \mathrm{CO}_{2}, 0.04 ; \mathrm{H}_{2} \mathrm{O}, 0.09 ; \mathrm{N}_{2}, 0.749925 ; \mathrm{NO}, 25 \times 10^{-6} ; \mathrm{O}_{2}, 0.12$. The residence time (reaction time) of the gas was assumed to be $2 \mathrm{~s}$.

The reaction mechanism was as follows: the mutual promotion of oxidation of $\mathrm{CO}$ and $\mathrm{NO}$ occurs through a three-step chain reaction mechanism of self-conduction [15-17].

As shown in Figure 3, the first step of the reaction is not to stabilize the pyrolysis of the substance, but to react slowly. The first two steps of the reaction produce the free radical $\mathrm{OH}$, thus initiating a chain reaction. Then, the third, fourth and fifth reactions lead to the oxidation of $\mathrm{NO}$ and $\mathrm{CO}$, and the three-step reactions do not have a net consumption of free radicals. When the temperature is less than $550{ }^{\circ} \mathrm{C}$, every mole of $\mathrm{CO}$ is oxidized into $\mathrm{CO}_{2}$, while one mole of $\mathrm{NO}$ is oxidized into $\mathrm{NO}_{2}$. At lower temperature $\left(<450{ }^{\circ} \mathrm{C}\right)$, the first step of the reaction is too slow to provide enough free radical $\mathrm{O}$.
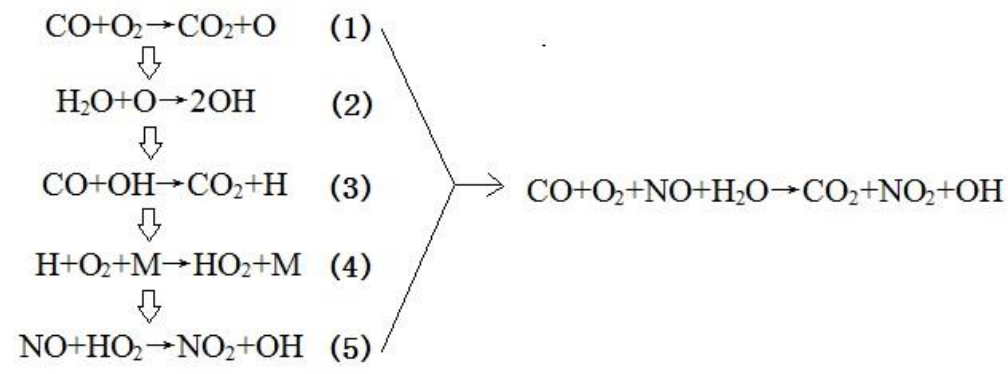

Figure 3. The chain reaction mechanism.

When the temperature is too high (above $650{ }^{\circ} \mathrm{C}$ ), free radical $\mathrm{H}$ is easily destroyed. If the free radical $\mathrm{H}$ is destroyed, it will lead to oxidation decoupling of $\mathrm{CO}$ and $\mathrm{NO}$. For example, as the temperature increases, the fourth step of the reaction will become weaker, and the free radical $\mathrm{H}$ is destroyed as follows:

$$
\mathrm{H}+\mathrm{O}_{2} \rightarrow \mathrm{OH}+\mathrm{O}
$$

When the temperature is about $850{ }^{\circ} \mathrm{C}$, about $50 \%$ of free radical $\mathrm{H}$ at the fourth step is destroyed, and the rest free radical $\mathrm{H}$ is destroyed by Reaction (6). In addition, only $20 \%$ of the consumed $\mathrm{HO}_{2}$ results in $\mathrm{NO}$ oxidation to $\mathrm{NO}_{2}$. The rest of free radical $\mathrm{HO}_{2}$ is destroyed as follows:

$$
\mathrm{HO}_{2}+\mathrm{OH} \rightarrow \mathrm{H}_{2} \mathrm{O}+\mathrm{O}_{2}
$$

The reactor was insulated from the outside and the temperature was set to be constant. From 400 to $950{ }^{\circ} \mathrm{C}$, the residence time of mixed gases in the reactor was $2 \mathrm{~s}$ at each temperature. 


\subsection{Experimental Research}

As shown in Figure 4, each gas was supplied by gas tanks, and the gases were mixed by a flow controller E according to a certain ratio, and the flow rate of the added water was controlled by the peristaltic pump F. The mixed gas entered the heating cable $G$ for preheating, and then entered the electric resistance furnace $\mathrm{H}$ for heating. The reacted gases were discharged through the smoke analysis instrument I. The controllable flow rate of the flow controller was $0-1000 \mathrm{~mL} / \mathrm{min}$, the temperature of the heating cable was controlled by the temperature controller, the maximum power of the resistance furnace was $1 \mathrm{~kW}$, the rated temperature was $900^{\circ} \mathrm{C}$, and the flow control range of the peristaltic pump was $0.00025-48 \mathrm{~mL} / \mathrm{min}$.

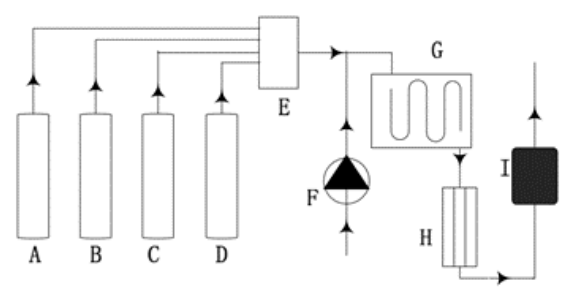

Figure 4. Test system: $\mathrm{A}, \mathrm{N}_{2}$ gas tank; $\mathrm{B}, \mathrm{O}_{2}$ gas tank; $\mathrm{C}, \mathrm{CO}$ gas tank; $\mathrm{D}, \mathrm{NO}$ gas tank; $\mathrm{E}$, flow controller; $\mathrm{F}$, peristaltic pump; $\mathrm{G}$, heating cable; $\mathrm{H}$, resistance furnace; I, smoke analysis instrument.

The residence time of the gas in the experiment was also about $2 \mathrm{~s}$, the same as the CHEMKIN software. The data of the four experiments were arithmetically averaged and compared with the data calculated by CHEMKIN software. As shown in Figure 5, the experimental and calculated NO conversion trends are basically the same. However, the peaks of the two results are in different temperature ranges. Because the gas stayed in the resistance furnace for a short period of time and was heated to the corresponding temperature in the experiment, it took more time. However, the results of the simulation calculations and the experiments are highly consistent in terms of trends.

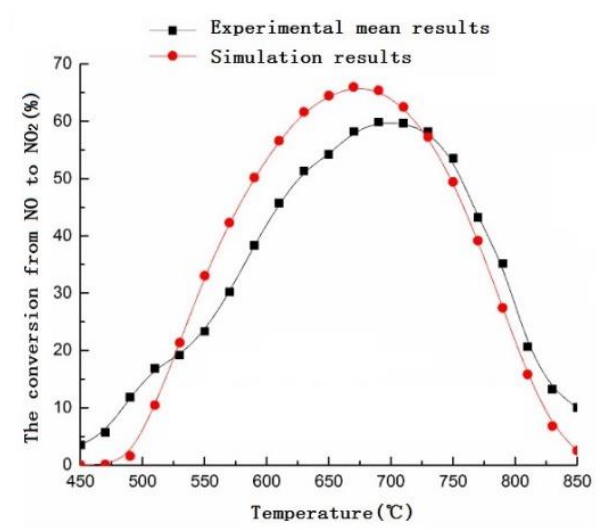

Figure 5. Effect of temperature on the conversion.

\subsection{Mechanism Analysis}

Figure 6 shows that, as the temperature increases, the NO conversion rate first increases and then decreases. In the interval of $650-700{ }^{\circ} \mathrm{C}$, the $\mathrm{NO}$ conversion rate reaches the highest, which is about $60 \%$. When the temperature is lower than $450{ }^{\circ} \mathrm{C}$ or higher than $850{ }^{\circ} \mathrm{C}$, the conversion rate of NO to $\mathrm{NO}_{2}$ is extremely low. Figure 6 shows that, when there is no $\mathrm{CO}$ in the inlet gas, the conversion of $\mathrm{NO}$ is very low. The conversion of $\mathrm{NO}$ significantly increases when the $\mathrm{CO}$ is introduced into the resistance furnace. The concentration of $\mathrm{CO}$ in flue gas is $50 \mathrm{ppm}$. It is indicated that $\mathrm{CO}$ has the effect of promoting the conversion of $\mathrm{NO}$ to $\mathrm{NO}_{2}$. 


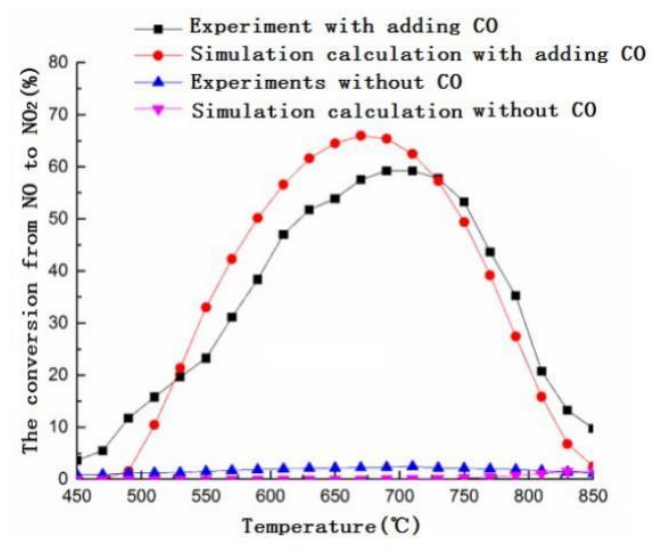

Figure 6. Effect of temperature and $\mathrm{CO}$ on the conversion.

Figure 7 shows that, as the volume fraction of the inlet $\mathrm{CO}$ increases, the conversion rate of NO increases, when the reaction temperature is $550-650{ }^{\circ} \mathrm{C}$. It takes a certain amount of time for the gas to be heated to the corresponding temperature during the experiment, but the gas stays in the resistance furnace for a short time. Thus, due to the limitation of the retention time, the experimental was not fully carried out under the ideal condition. As a result, the conversion rate of the simulation calculation is higher than that of the experiment.

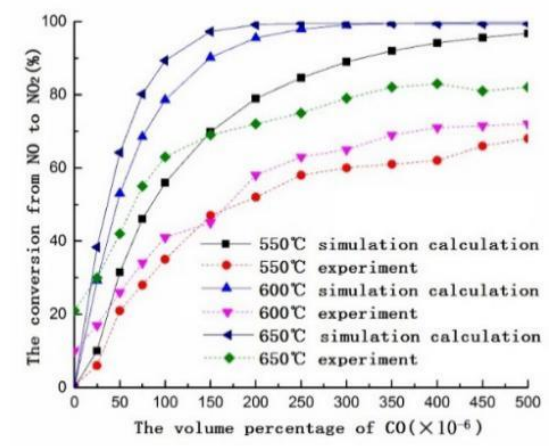

Figure 7. Effect of $\mathrm{CO}$ concentration on the conversion.

Figure 8 shows that, in the experiment, the $\mathrm{O}_{2}$ concentration change has little effect on the conversion of $\mathrm{NO}$ to $\mathrm{NO}_{2}$. When the oxygen concentration reaches $12 \%$ or more and the reaction temperature is around $650{ }^{\circ} \mathrm{C}$, the conversion rate of $\mathrm{NO}$ in the experiment is basically maintained at $40-50 \%$. However, if there is no oxygen, the conversion rate will be very low.

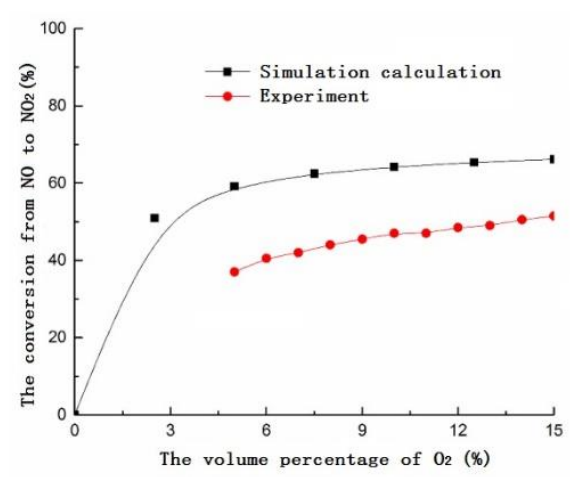

Figure 8. Effect of $\mathrm{O}_{2}$ concentration on the conversion.

Figure 9 shows that the $\mathrm{NO}$ to $\mathrm{NO}_{2}$ conversion rate decreases with the increase of the inlet $\mathrm{NO}$ volume fraction when the reaction temperature is around $650{ }^{\circ} \mathrm{C}$. Because $\mathrm{NO}$ and $\mathrm{NO}_{2}$ are 
contaminants, it is not recommended to reduce the conversion rate from $\mathrm{NO}$ to $\mathrm{NO}_{2}$ by increasing the concentration of NO.

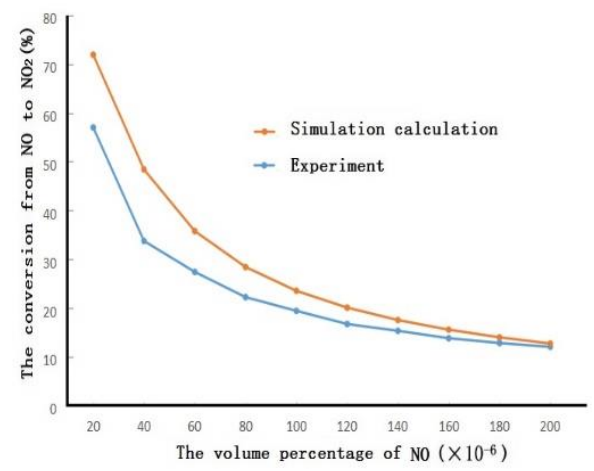

Figure 9. Effect of NO concentration on the conversion.

Figure 10 shows that, in the absence of water vapor, the NO conversion ratio is lower. The NO conversion ratio in the experiment is slightly higher than the calculation results, but it is still below $10 \%$. When water is added, the volume fraction of water vapor reaches $9 \%$, and the conversion rate is greatly improved. Therefore, water vapor is an important condition for the conversion of $\mathrm{NO}$ to $\mathrm{NO}_{2}$.

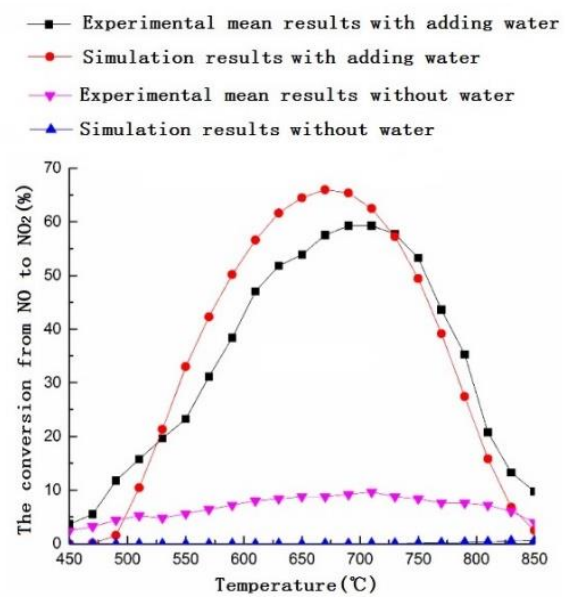

Figure 10. Effect of water vapor on the conversion.

In the experiment on water vapor, the residual gas was discharged using $\mathrm{N}_{2}$ at the end of the experiment, and the sudden expansion and shrinkage section in the heater caused a small portion of the gas residue, which may have resulted in a small portion of the gas residue in the heating furnace. Therefore, the conversion rate without water addition in experiment is higher than the conversion rate of simulated calculation.

During the start-up period of the gas turbine, the main factors affecting the generation of yellow plume are the $\mathrm{CO}$ content and temperature. $\mathrm{CO}$, which is produced by incomplete combustion, is the main influencing factor of $\mathrm{NO}$ conversion to $\mathrm{NO}_{2}$. At the temperature range of $600-700{ }^{\circ} \mathrm{C}$, the concentration ratio of $\mathrm{NO}$ to $\mathrm{NO}_{2}$ is the highest. Simultaneously, the oxygen content and water vapor content in the flue gas are important influencing factors of the generation of yellow plume. The presence of oxygen and water vapor has a significant impact on conversion rates, but, if oxygen and water vapor are present and reach a certain concentration, then the effect of increased concentration on the conversion rate is less pronounced. 


\section{On-Site Measurement of the $6 \mathrm{~F}$ Unit}

To verify the influencing factors of yellow plume, the author chose a gas and steam combined cycle unit for on-site measurement. The PG 6111FA+E unit was selected for this test. The unit is equipped with DLN2.6 burners. The burners are improved compared to DLN2.0+ burners [18]. Each combustion chamber has 1 PM1 nozzle, 2 PM2 nozzles, 3 PM3 nozzles and 15 QUAT nozzles, as shown in Figure 11. The PM1 nozzle is placed in the center, the PM2 and PM3 nozzles are evenly arranged around the PM1, and the 15 QUAT nozzles are placed at the edge of the combustion chamber. The fully premixed combustion mode [19] is adopted in the burners.

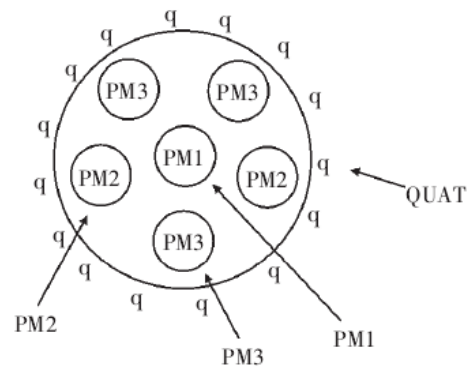

Figure 11. Nozzles arrangement of DLN-2.6 burners.

To analyze the effect of the internal environment of the HRSG on the conversion from $\mathrm{NO}$ to $\mathrm{NO}_{2}$, the positions of the measuring points are marked in the red circles of Figure 12: Test Point 1 is the inlet position of the diffusing section, Test Point 2 is the inlet position of the HRSG, and the Point 3 is the outlet of the chimney of the HRSG.

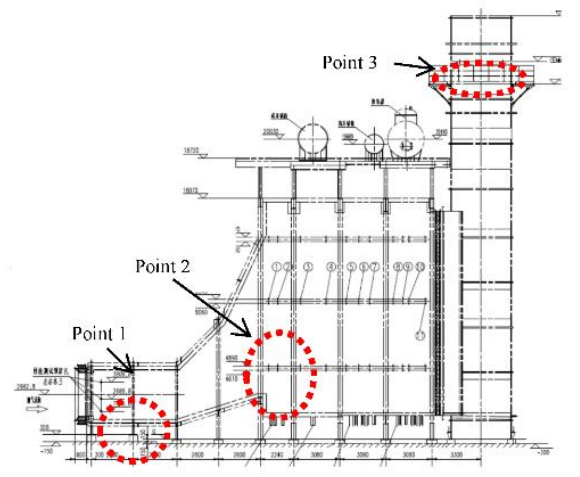

Figure 12. Arrangement of measuring points in the HRSG.

At the on-site test, the yellow plume was produced more under the low-load conditions (lower than $50 \%$ rated load) of start-up process, as shown in Figures 13 and 14. Yellow plume is caused by high $\mathrm{NO}_{2}$ content in the exhaust.

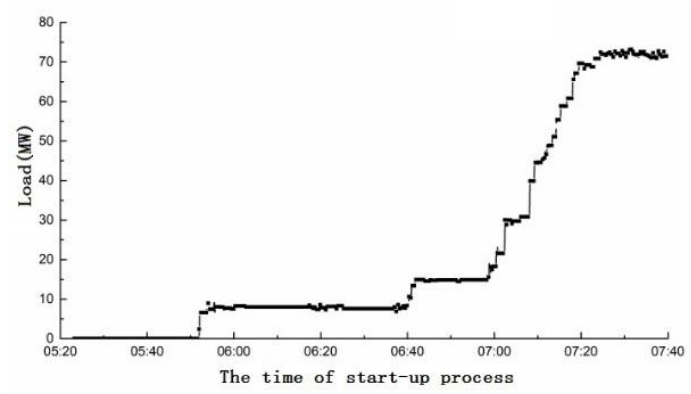

Figure 13. The load change during the start-up period. 


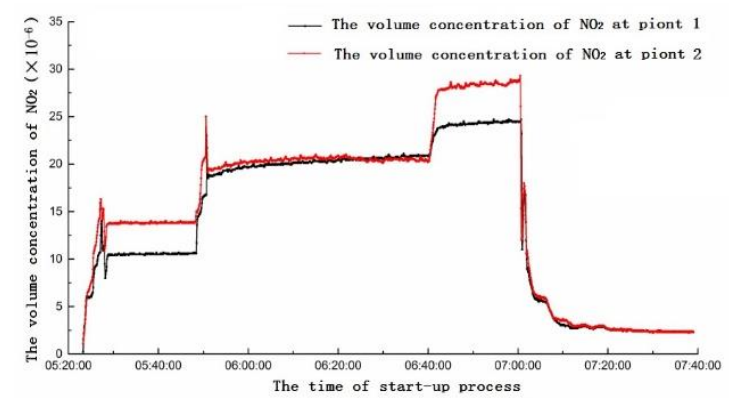

Figure 14. $\mathrm{NO}_{2}$ measurements at Point 1 and Point 2 .

\subsection{Analysis of Yellow Plume Formation at Different Stages of the Start-Up Period}

During the start-up period of the gas turbine, when the unit has no load, the $\mathrm{NO}_{2}$ is mainly generated from the combustion chambers of gas turbine and the diffusion section where the conversion from $\mathrm{NO}$ to $\mathrm{NO}_{2}$ happens because of rich-oxygen. As can be seen in Figures 13-15, when the gas turbine reaches a load of $10 \mathrm{MW}$, the exhaust temperature of the gas turbine reaches $500{ }^{\circ} \mathrm{C}$, and the $\mathrm{NO}_{2}$ is mainly from the combustion chambers of gas turbine. As can be seen in Figures 15-17, when the gas turbine reaches the load of $14-15 \mathrm{MW}$, the exhaust gas temperature reaches $600{ }^{\circ} \mathrm{C}$, the $\mathrm{CO}$ and oxygen concentrations are sufficient, and the $\mathrm{NO}_{2}$ in the exhaust comes from two parts: one is produced in the combustion chambers of gas turbine, and the other is produced by the conversion of $\mathrm{NO}$ to $\mathrm{NO}_{2}$ in diffusion section, which connects the gas turbine with the HRSG.

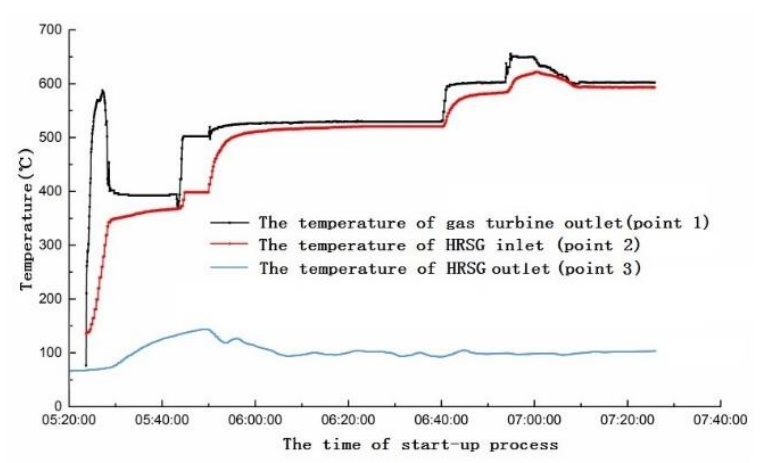

Figure 15. The flue gas temperature of turbine outlet and HRSG inlet.

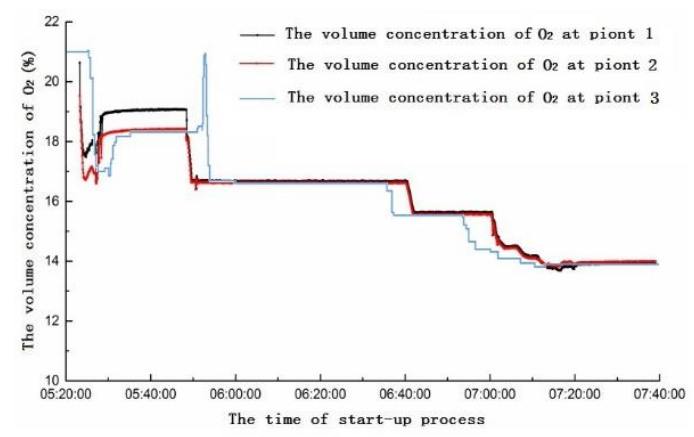

Figure 16. Oxygen concentration at Point 1 and Point 2. 


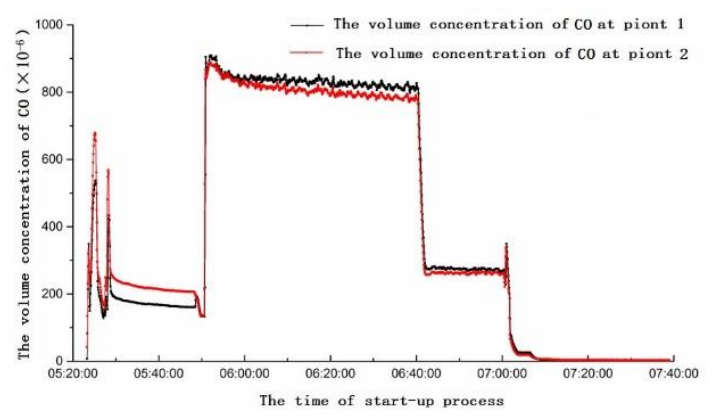

Figure 17. CO concentration at Point 1 and Point 2.

\subsection{Analysis of the Position of Yellow Plume Formation in HRSG}

In the HRSG, the conversion of $\mathrm{NO}$ into $\mathrm{NO}_{2}$ occurs in the diffusion section. The main reasons that the reaction conditions convert $\mathrm{NO}$ to $\mathrm{NO}_{2}$ are provided. The temperature is high (close to the turbine exhaust temperature), the concentrations of carbon monoxide and oxygen are sufficient, and residence time (reaction time) is enough (about $1 \mathrm{~s}$ ). When the flue gas enters the heat exchange surface of the HRSG, it is rapidly cooled to below $500{ }^{\circ} \mathrm{C}$, and then the conversion reaction becomes slow. In Figures 18 and 19, it can be seen that the process of converting from $\mathrm{NO}_{2}$ to $\mathrm{NO}$ happens in the region between Point 2 and Point 3 from 6:00 to 6:40.

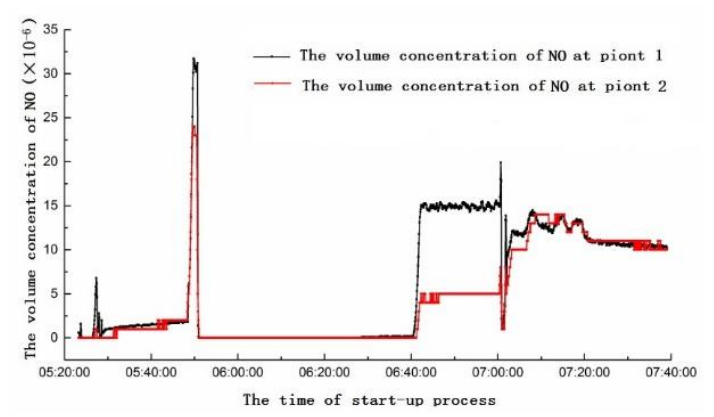

Figure 18. NO concentration at Point 1 and Point 2.

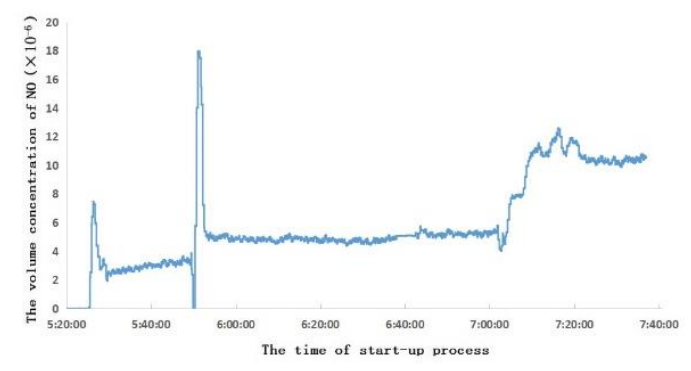

Figure 19. NO concentration at Point 3.

\section{Analysis of Countermeasures for Yellow Plume}

\subsection{Discussion on Control Measures from Gas Turbine Side}

The yellow plume is mainly from the gas turbine side. As shown in Figure 20, the nozzles of the $6 \mathrm{~F}$ unit are adjusted during the start-up period. As shown in Figure 21, the fuel flow rate and the opening angle of the compressor inlet guide vanes (IGV) of the $6 \mathrm{~F}$ unit are changing during the start-up period. 


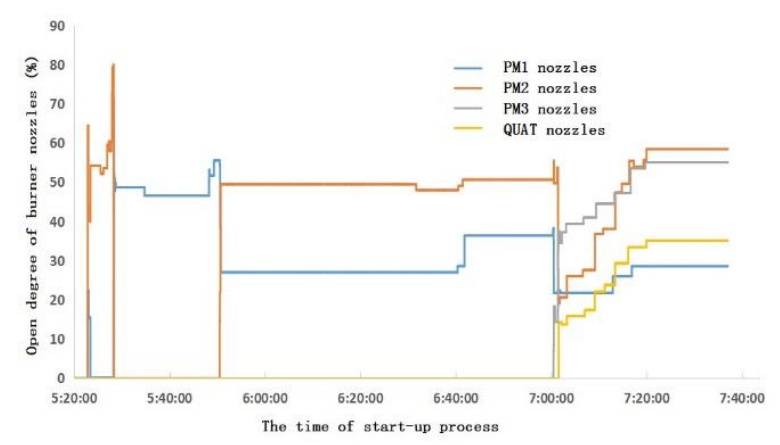

Figure 20. Open degree of burner nozzles during the start-up period.

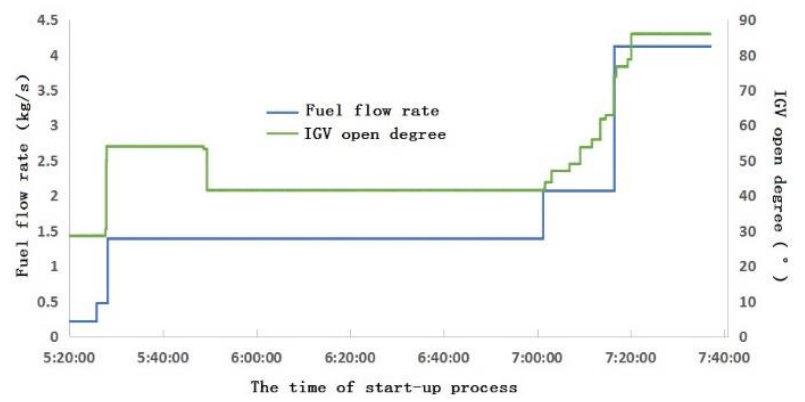

Figure 21. Open degree of inlet guide vanes (IGV) and fuel flow rate during the start-up period.

During the start-up period, the burner adjustment and unit pollutant emission are summarized as follows:

(1) The gas turbine starts to ignite, PM1 and PM2 open simultaneously. With the success of ignition, gas flow of PM2 gradually increases, while gas flow of PM1 gradually decreases. When only the PM2 nozzle is opened, the NO is relatively low. When the open degree of PM2 reaches $80 \%$, there is a sudden increase of $\mathrm{NO}$ concentration.

(2) When the rated speed of gas turbine reaches 95\%, PM1 nozzle begins to open, while PM2 gradually reduces the amount of fuel until the fuel valve is fully closed. When only PM1 nozzle is open, the unit and the NOx concentrations change little. Then, the unit starts to connect to the grid.

(3) When the gas turbine is connected to the grid successfully and begins to load up, the combustion mode is switched over and PM2 is put into operation. In the switching process, the combustion temperature is relatively high, and the NO reaches the highest value. With the open degrees of PM2 and PM1 entering a stable state, the $\mathrm{NO}$ rapidly drops back to normal, and the $\mathrm{NO}_{2}$ enters a stable and high concentration period. After that, the open degree of PM1 increases, and the gas turbine load increases. With the increase of combustion temperature, $\mathrm{NO}$ concentration increases slightly from the previous stage, and $\mathrm{NO}_{2}$ enters the highest concentration period.

(4) When the gas turbine needs to increase to the base load, the combustion mode changes again. The open degrees of PM2 and PM1 decrease, PM3 and QUAT nozzles gradually open, and the switching moment has the characteristics of sudden increase of NO concentration. After switching successfully, PM1, PM2, PM3 and QUAT nozzles all open. Then, the nozzles gradually increase open degree, and the gas engine load increase. At this time, the combustion temperature of gas turbine increases gradually, the concentration of $\mathrm{NO}$ increases gradually, and the concentration of $\mathrm{NO}_{2}$ has a gradual downward trend. Because the open degree of each nozzle is changing, the concentration of NO has small fluctuations. Although PM1 is in premixed mode, its fuel coefficient (fuel equivalent ratio) is relatively high, which plays a role in stabilizing the flame and adjusting combustion dynamic stability. PM2 and PM3 nozzles are in the lean combustion limit region or even slightly lower. Subsequently, the gas turbine reaches the stable base load; at this 
time, the fuel flow rate of each nozzle reaches the optimal ratio, and the concentrations of NO and $\mathrm{NO}_{2}$ reach a steady low state.

Based on the above research and analysis, several measures to suppress the yellow plume from the gas turbine side are proposed as follows:

(1) The time from the unit being connected to the grid successfully to full load should be reduced, and the rate of load rise needs to increase. For the $6 \mathrm{~F}$ unit, the running time of PM1 + PM2 premixed mode should be reduced to shorten the yellow plume time.

(2) The start-up strategy of the gas turbine should be adjusted. The exhaust temperature of gas turbine during the start-up period should not exceed $500{ }^{\circ} \mathrm{C}$ to reduce the $\mathrm{NO}$ conversion to $\mathrm{NO}_{2}$ in the HRSG, which can alleviate the phenomenon of yellow plume.

(3) The combustion efficiency during the start-up period should be increased, then the content of $\mathrm{CO}$ is reduced, thus the yellow plume could be alleviated. For example, upgrading the combustion system of the gas turbine could make $\mathrm{CO}$ in the combustion chamber stay a sufficient time to complete combustion, thus the content of $\mathrm{CO}$ is reduced.

\subsection{Discussion on Control Measures from the HRSG Side}

As shown in Figure 15, the exhaust temperature of gas turbine and the inlet temperature of the HRSG can reach about $600{ }^{\circ} \mathrm{C}$. This temperature range makes $\mathrm{NO}$ transform rapidly to $\mathrm{NO}_{2}$, which makes the $\mathrm{NO}_{2}$ content at Test Point 2 obviously higher than at Test Point 1 . At the same time, due to the existence of $\mathrm{CO}, \mathrm{O}_{2}, \mathrm{H}_{2} \mathrm{O}$ and other appropriate factors, the conversion conditions of $\mathrm{NO}$ to $\mathrm{NO}_{2}$ are better in the HRSG.

Based on the above research and analysis, several measures to suppress yellow plume from the HRSG side are proposed as follows:

(1) CO catalytic oxidation device [20] should be installed in the diffusion section, which connects the gas turbine with the HRSG, which can reduce the content of $\mathrm{CO}$ and $\mathrm{NO}_{2}$. Simultaneously, the flue gas temperature should rise to improve the efficiency of the HRSG.

(2) Catalytic reduction method [21] should be adopted in the flue. $\mathrm{Th}^{\mathrm{NO}} \mathrm{N}_{2}$ would be reduced to $\mathrm{NO}$, thus yellow plume would be eliminated.

(3) The flue gas should be sprayed and $\mathrm{NO}_{2}$ absorbed in the flue or chimney of the HRSG [22], thus the sewage would be neutralized by alkaline substances, or the alkaline solution could be directly sprayed inside the chimney.

\section{Conclusions}

Based on the analysis of yellow plume emission during the gas turbine start-up period, the key factors of yellow plume generation were analyzed by means of simulation analysis and mechanism experiment. It is summarized that temperature and $\mathrm{CO}$ concentration are the two factors that have the greatest impact on yellow plume, while water vapor and oxygen are also essential conditions.

Combined with $6 \mathrm{~F}$ gas turbine unit on-site test results, it is summarized that the production of $\mathrm{NO}_{2}$ is mainly from the gas turbine side, and the conversion of $\mathrm{NO}$ to $\mathrm{NO}_{2}$ in the HRSG is mainly from the expansion section, which connects the gas turbine with the HRSG. Based on the above research, the paper proposes several measures to suppress yellow plume from the gas turbine side and the HRSG side.

Author Contributions: Conceptualization, Z.L. and K.W.; methodology Y.L.; software, C.S.; validation, Y.L., W.S. and B.W.; formal analysis, C.S.; investigation, Y.L.; resources, Z.L.; data curation, W.S.; writing-original draft preparation, Y.L..; writing-review and editing, Z.L.; visualization, K.W.; supervision, B.W.; project administration, K.W.; funding acquisition, Z.L.

Funding: The financial support of this project was provided by Jiangsu province "six talents summit" high-level talent selection and training funding scheme in China under grant number JNHB-080.

Conflicts of Interest: The authors declare no conflict of interest. 


\section{References}

1. Liu, Z.; Li, Y.; Wang, K. The Environmental Protection Status Quo of China's gas Power Plants and the Trending in Policies. Electr. Power 2018, 51, 147-153.

2. Liu, Z.; Wang, K.; Li, Y. Study on denitration scheme of gas power plant based on environmental protection standard. Electr. Power Technol. Environ. Prot. 2017, 33, 18-21.

3. Tuttle, J.H.; Shisler, R.A.; Mellor, A.M. Nitrogen Dioxide Formation in gas Turbine Engines: Measurements and Measurement Methods. Combust. Sci. Technol. 1974, 9, 261-271. [CrossRef]

4. Laurendeau, N.M. Fast Nitrogen Dioxide Reactions: Significance during NO Decomposition and $\mathrm{NO}_{2}$ Formation. Combust. Sci. Technol. 1975, 11, 89-96. [CrossRef]

5. Chen, R.H. NOx and $\mathrm{NO}_{2}$ Emission of Swirl-Stabilized Nonpremixed Flames of a $\mathrm{H}_{2} / \mathrm{CH}_{4} \mathrm{Mixture}$. Combust. Sci. Technol. 2012, 120, 321-333. [CrossRef]

6. Schäfer, K.; Brockmann, K.; Heland, J.; Wiesen, P.; Jahn, C.; Legras, O. Multipass open-path Fourier-transform infrared measurements for nonintrusive monitoring of gas turbine exhaust composition. Appl. Opt. 2005, 44, 2189. [CrossRef] [PubMed]

7. Feitelberg, A.S.; Correa, S.M. The Role of Carbon Monoxide in $\mathrm{NO}_{2}$ Plume Formation. In ASME 1999 International Gas Turbine and Aeroengine Congress and Exhibition; American Society of Mechanical Engineers: New York, NY, USA, 2000; p. V002T02A005.

8. Sorrentino, G.; Sabia, P.; Bozza, P.; Ragucci, R.; de Joannon, M. Impact of external operating parameters on the performance of a cyclonic burner with high level of internal recirculation under MILD combustion conditions. Energy 2017, 137, 1167-1174. [CrossRef]

9. Galbiati, M.A.; Cavigiolo, A.; Effuggi, A.; Gelosa, D.; Rota, R. Mild combustion for fuel-NOx reduction. Combust. Sci. Technol. 2004, 176, 1035-1054. [CrossRef]

10. Xu, H.; Hu, D.; Zhou, X.; Liu, H. Study on NOx emission from gas turbine and denitrification technology. Energy Environ. 2017, 5, 29-31.

11. Wang, W.; Hua, W.; Sun, H. The causes and solutions of gas turbine chimney emission yellow smoke. Electr. Power Technol. Environ. Prot. 2016, 32, 33-35.

12. Institute of Power Machinery and Engineering, Department of Thermal Engineering, Tsinghua University. Gas Turbine and Gas-Steam Combined Cycle Device; China Electric Power Press: Beijing, China, 2007.

13. Zhu, B. Chemical Reaction Engineering; Chemical Industry Press: Beijing, China, 2012.

14. Wei, Y.; Zhang, D.; Ran, B.; Mao, Y. SCR Process Simulation and Test Study Based on Catalytic Reaction Kinetics. Dongfang Electr. Rev. 2015, 29, 14-19.

15. Yao, Q.; Li, S.; Wang, Y. Introduction to Combustion: Concept and Application; Tsinghua University Press: Beijing, China, 2008.

16. Turns, S.R. An Introduction to Combustion Conceps and Applications; The McGraw-Hill Companies, Inc.: New York, NY, USA, 2000.

17. Glassman, I. Combustion; Academic Press: Orlando, FL, USA, 2008.

18. Cai, G. Application of fully premixed DLN2.6+ combustor in China. Power Energy 2017, 38, 315-319.

19. Lou, H.; Chen, X.; Mao, Z. Brief Analysis of DLN-2.6 Combustion System of GE gas Turbine. Zhejiang Electr. Power 2011, 30, 70-73.

20. McDeed, D.; Pyros, G.; Bravato, A. Operating A Gas Turbine Power Plant at Low Load Conditions. U.S. Patent 2015/011563, 23 July 2015.

21. Yang, J.H.; Yang, J.; Chun, D.H.; Kim, H.; Lee, H.; Jung, H. Catalytic process for decolorizing yellow plume. Korean J. Chem. Eng. 2011, 28, 418-423. [CrossRef]

22. Zhou, Y.; Wang, Z.; Cheng, S.; Li, P.; Xue, Z.; Shao, J. A Device for Eliminating Yellow Smoke from Chimneys in the Early Stages of Gas Turbine Startup. Patent CN107261842A, 20 October 2017.

(C) 2019 by the authors. Licensee MDPI, Basel, Switzerland. This article is an open access article distributed under the terms and conditions of the Creative Commons Attribution (CC BY) license (http:/ / creativecommons.org/licenses/by/4.0/). 